\title{
Osteomyelitis of the Hip secondary to Aspergillus fumigatus - A Case Report and Comprehensive Review of the Literature
}

\author{
Antony $\mathrm{SJ}^{\star 1,2}$ and Hadi $\mathrm{Y}^{1}$ \\ ${ }^{1}$ Texas Tech University Health Science Center, El Paso, Texas \\ ${ }^{2}$ Center for Infectious Disease and Travel Medicine, El Paso, Texas
}

${ }^{*}$ Corresponding author: Antony SJ, M.D, Texas Tech University Health Science Center, El Paso, Texas, 1205

N. Oregon, El Paso, TX 79902, Fax: (915)533-4902, Tel: (915)533-4900, E-mail: suresh.antony@att.net

Citation: Antony SJ, Hadi Y (2014) Osteomyelitis of the Hip secondary to Aspergillus fumigatus - A Case Report and Comprehensive Review of the Literature. J Immunol Infect Dis 1(1): 105. doi: 10.15744/23946512.1.105

\section{Received Date: September 15, 2014 Accepted Date: October 03, 2014 Published Date: October 07, 2014}

\section{Introduction}

Aspergillus infection in an immunocompetent human host is a rare entity. In most cases it presents as an opportunistic pathogen in immunocompromised patients. The portal of entry is usually the respiratory tract or direct inoculation of the organism to the site. Aspergillus osteomyelitis is a debilitating and severe form of Invasive Aspergillosis.

This paper presents a case of osteomyelitis of the hip without a recent obvious source of entry and reviews the literature of osteomyelitis and bone infections caused by Aspergillus.

\section{Case Report}

This is a 70 year-old male with past medical history of Chronic Obstructive Pulmonary Disease (COPD), Hypothyroidism, Bilateral Inguinal Hernia (repaired in 2006) and Benign Prostate Hypertrophy. His home medication prior to this event were Synthroid 100 mcg daily and Montelukast $10 \mathrm{mg}$ daily.

The patient was evaluated for a persistent mild cough without fever, chills, chest pain or any muscular or musculoskeletal pain. During the process of this particular illness, he complained of pain to the right hip. Further work up three months later revealed increasing pain localized to the right hip, non-radiating, severe in nature, aggravated with walking and weight bearing. At that time, he denied any trauma to the area or any direct injury to any related area.

A Magnetic Resonance Imaging (MRI) of right hip was done and showed evidence of osteomyelitis of the right sacral iliac joint. He underwent a biopsy of the right iliac joint. The gram stain of biopsy did not show any bacteria/organism with normal White Blood Cell (WBC) and Red Blood Cell (RBC) count. However, the pathology revealed extensive fibrosis, focal necrosis and osteomyelitis. In addition, the culture grew Aspergillus fumigatus species. Further workup did not reveal the primary source of infection especially in the lung. Susceptibility studies were not done unfortunately.

A bronchoalveolar lavage was done because a small speculated lesion in the right lower lobe. This was unremarkable for malignant cells, fungal organisms or acid-fast bacilli. Complete blood count and comprehensive metabolic panel was unremarkable. Erythrocyte Sedimentation Rate (ESR) was $90 \mathrm{~mm} /$ hour and C-Reactive Protein (CRP) was 4.5.

The patient was started on oral Voriconazole $200 \mathrm{mg}$ once a day for six months. He tolerated the therapy without much problem. The MRI done of the right hip six months later revealed stabilization of the osteomyelitis.

\section{Discussion}

Fungal osteomyelitis, mainly caused by Candida $s p$ and Aspergillus $s p$, is a severe and debilitating disease [1]. It is primarily a disease of the immunocompromised patients, even though it can affect immunocompetent patients. The majority of the cases have been reported in developed regions with outstanding healthcare systems, such as North America (47\% of the reported cases) and Europe (33\% of the reported cases). The most common mode of transmission of Aspergillus osteomyelitis is contiguous spread from pulmonary infection and/or from contiguous skin infection. This may be the reason why the vertebrae and the ribs were the most common sites affected [2]. In adults, vertebrae is also the most common infection site but most of the time due to hematogenous spread or direct inoculation due to trauma with penetrating injury/surgical procedures [2-7]. Most cases of Aspergillus osteomyelitis appeared to be affecting immunocompromised hosts with chronic granulomatous infections and immunodeficiency condition [2,46,8-10]. Among adults, prolonged and high dose immunosuppressive drug therapy is considered the most important predisposing condition $[2,4]$. 
In a paper published in 1999, a review of the literature on fungal osteomyelitis was done, which revealed less than 40 cases of Aspergillus osteomyelitis. Noticeably, the increased usage of chemotherapy, immunomodulator and steroids may indirectly cause the increased incidence of Invasive Aspergillosis, in particular Aspergillus osteomyelitis. Other important risk factors that should be considered are the use of central venous catheters and abdominal surgery. Therefore, in our case, it is possible that the history of bilateral inguinal hernia repair may have played a role as an entry route of Aspergillus fumigatus.

The incidence of Aspergillus affecting the bone among all cases of invasive Aspergillosis is thought to be around 3\% [11,12]. In a series by Horn et al, the incidence of invasive Aspergillosis was 2.6\%, similar to those reported by Denning and Stephen in 1990 [12]. In most cases it appears to present as diskitis or osteomyelitis of the spine. Involvement of the long bones and hip etc. has rarely been documented [3,4].

Aspergillus infection remains extremely rare in immunocompetent hosts [13]. In 1987, Brown et al reported 2 cases of seemingly immunocompetent adults who used intravenous drugs [14]. Vaishya et al reported a case of vertebral osteomyelitis in an immunocompetent adult; noting only 4 other cases have been previously reported [15]. In 2005, Mouas et al discussed 20 cases of osteomyelitis, 6 of which were immunocompetent [13].

Our case is particularly unique not only because the patient is immunocompetent, but also this is one of a few case of Aspergillus osteomyelitis that affecting long bone, particularly hip joint. There were no history of penetrating trauma/surgical event to the hip joint nor any signs of affected portal of entry of Aspergillus infection; which are lung, skin, gastrointestinal tract or sinuses [8].

It requires three major criteria to document that the osteomyelitis is secondary to a fungus:

1. Accurate identification and isolation of the pathogen from the actual site of infection.

2. Direct microscopic demonstration of the pathogenic invasive form of the fungus from the site where the cultures were obtained.

3. Correlation of the results of the culture to the osteomyelitis process. Concomitant bacterial infections can occasionally occur in these fungal bone infections.

Aspergillus fumigatus was the most commonly isolated species followed by Aspergillus flavus, Aspergillus niger, Aspergillus terreus [4,5,7]. Unlike Candida, which is the most common organism causing mycotic infections [16,17], Aspergillus is slow growing, difficult to isolate and most of the time is a contaminant since the spores are really small $[9,18]$. Therefore, a culture and histopathological examination are still important to obtain the correct diagnosis $[7,9,18]$.Another proposed method for diagnostic are Galactomannan (GM) and $(1 \rightarrow 3)$ - $\beta$-d-glucan $(B G)$ antigen quantification by enzyme-linked immunosorbent assay and detection of fungal DNA by PCR methods or single nucleotide polymorphism (SNP) markers. This test is not easily available and has not been studied as an indicator for osteomyelitis caused by Aspergillus.

Treatment for Aspergillus osteomyelitis includeAmphotericin B [2,19,20], Itraconazole [12,21] and Voriconazole [10,13,17,21,22]. Antifungal therapy in combination with surgical debridement of the bone involved is indicated, especially in advanced cases [12].

Recent studies of patients with invasive Aspergillosis have shown that treatment with Voriconazole is more effective than treatment with Amphotericin B [7,10,23,24]. Length of therapy is generally between 6-12 weeks [1,7]. Many of the literature supports the use of prolonged therapy for up to a year [13]. Recurrences are not uncommon [25].

\section{REPORTED CASES OF INVASIVE ASPERGILLUS INFECTIONS}

\begin{tabular}{|c|c|c|c|c|c|c|}
\hline Source & Age/Sex & Sites of infection & Predisposing condition & Diagnosis & Treatment & Course \\
\hline Agarwal et al. & $34 / \mathrm{M}$ & $\begin{array}{l}\text { Nasal polyp, right } \\
\text { maxillary antrum } \\
\text { and orbit }\end{array}$ & Not specified & $\begin{array}{l}\text { Histology and culture } \\
\text { of nasal polyp and } \\
\text { orbital tissue }\end{array}$ & $\begin{array}{l}\text { Surgery, X-radiation, } \\
\text { Iodine \& Hyamycin }\end{array}$ & Poor response \\
\hline Allen et al. & $67 / F$ & Sternum & $\begin{array}{l}\text { Hodgkin's Disease in remis- } \\
\text { sion }\end{array}$ & $\begin{array}{l}\text { Histology and culture } \\
\text { of open biopsy of } \\
\text { sternum }\end{array}$ & $\begin{array}{l}\text { Surgery debridement, } \\
\text { liposomal Ampho- } \\
\text { tericin B and oral } \\
\text { Itraconazole }\end{array}$ & Recovered \\
\hline Asare et al. & $69 / \mathrm{M}$ & $\begin{array}{l}\text { Sternum and left } \\
3^{\text {rd }} \text { coastal rib }\end{array}$ & None & $\begin{array}{l}\text { Histology and culture } \\
\text { of open biopsy of } \\
\text { sternum }\end{array}$ & $\begin{array}{l}\text { Surgery debridement, } \\
\text { intravenous and oral } \\
\text { Voriconazole }\end{array}$ & Recovered \\
\hline Asdamongkol et al. & $57 / \mathrm{M}$ & $\begin{array}{l}\text { C6-T4 vertebrae } \\
\text { and disk space }\end{array}$ & Remote history of TB, DM & $\begin{array}{l}\text { Histology and culture } \\
\text { of open biopsy material } \\
\text { from T4- } 5 \text { disk space }\end{array}$ & $\begin{array}{l}\text { Intravenous Ampho- } \\
\text { tericin B and oral } \\
\text { Itraconazole }\end{array}$ & Recovered \\
\hline $\begin{array}{l}\text { Baez-Escudero } \\
\text { et al. }\end{array}$ & $75 / \mathrm{M}$ & Sternum & $\begin{array}{l}\text { Chronic Lymphocytic Leu- } \\
\text { kemia with chemotherapy }\end{array}$ & $\begin{array}{l}\text { Histology and culture } \\
\text { of open biopsy material } \\
\text { from sternum }\end{array}$ & $\begin{array}{l}\text { Intravenous Ampho- } \\
\text { tericin B, oral Vori- } \\
\text { conazole and multiple } \\
\text { surgery debridement }\end{array}$ & Recovered \\
\hline Bathoorn et al. & $19 / \mathrm{M}$ & Left Maxilla & $\begin{array}{l}\text { Non-myeloblative stem cell } \\
\text { transplantation for graft } \\
\text { failure }\end{array}$ & $\begin{array}{l}\text { Histology and culture } \\
\text { of the bone fragments }\end{array}$ & $\begin{array}{l}\text { Intravenous Ampho- } \\
\text { tericin B and oral } \\
\text { Voriconazole }\end{array}$ & Recovered \\
\hline
\end{tabular}


REPORTED CASES OF INVASIVE ASPERGILLUS INFECTIONS

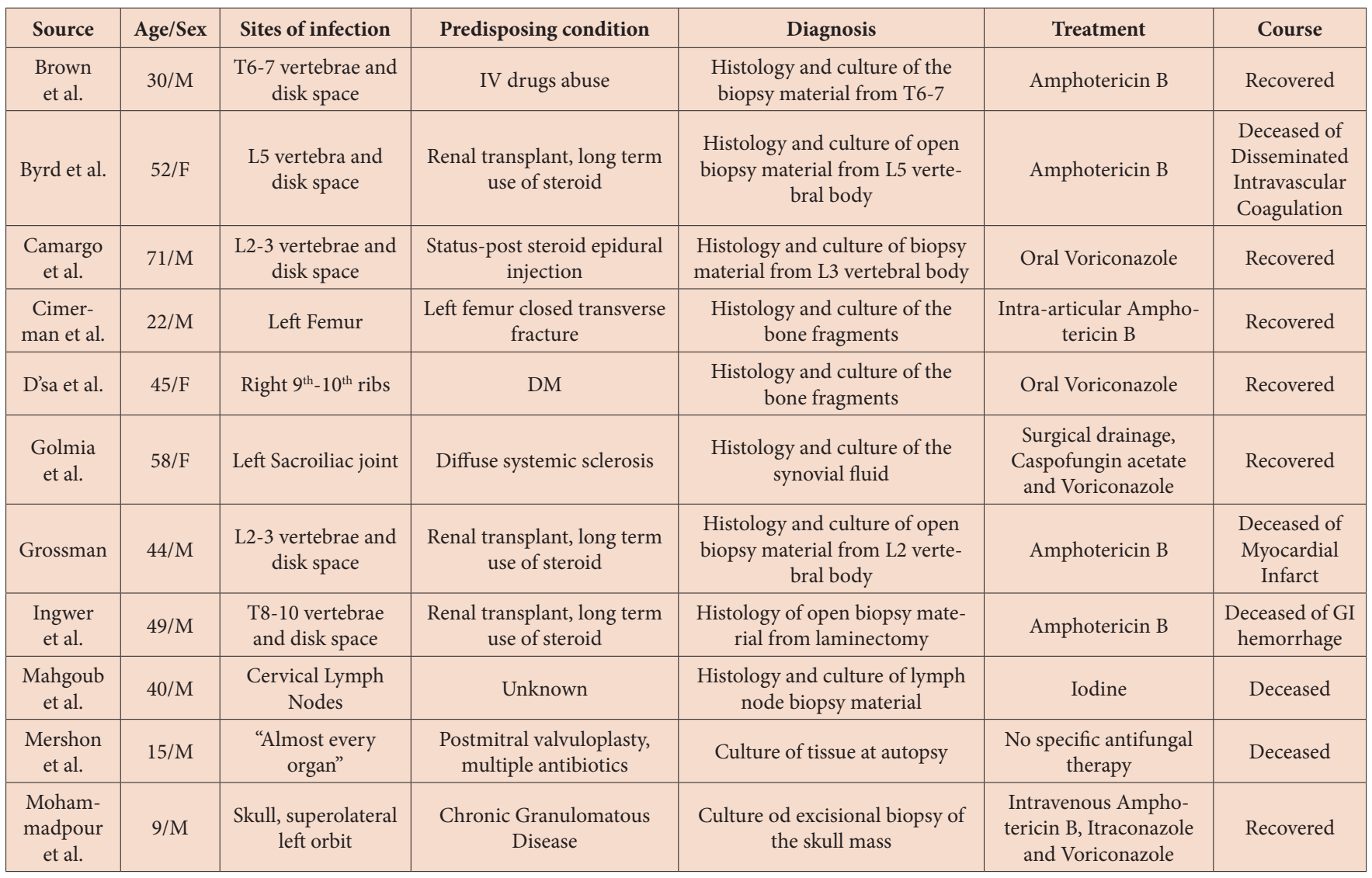

\section{REPORTED CASES OF INVASIVE ASPERGILLUS INFECTIONS}

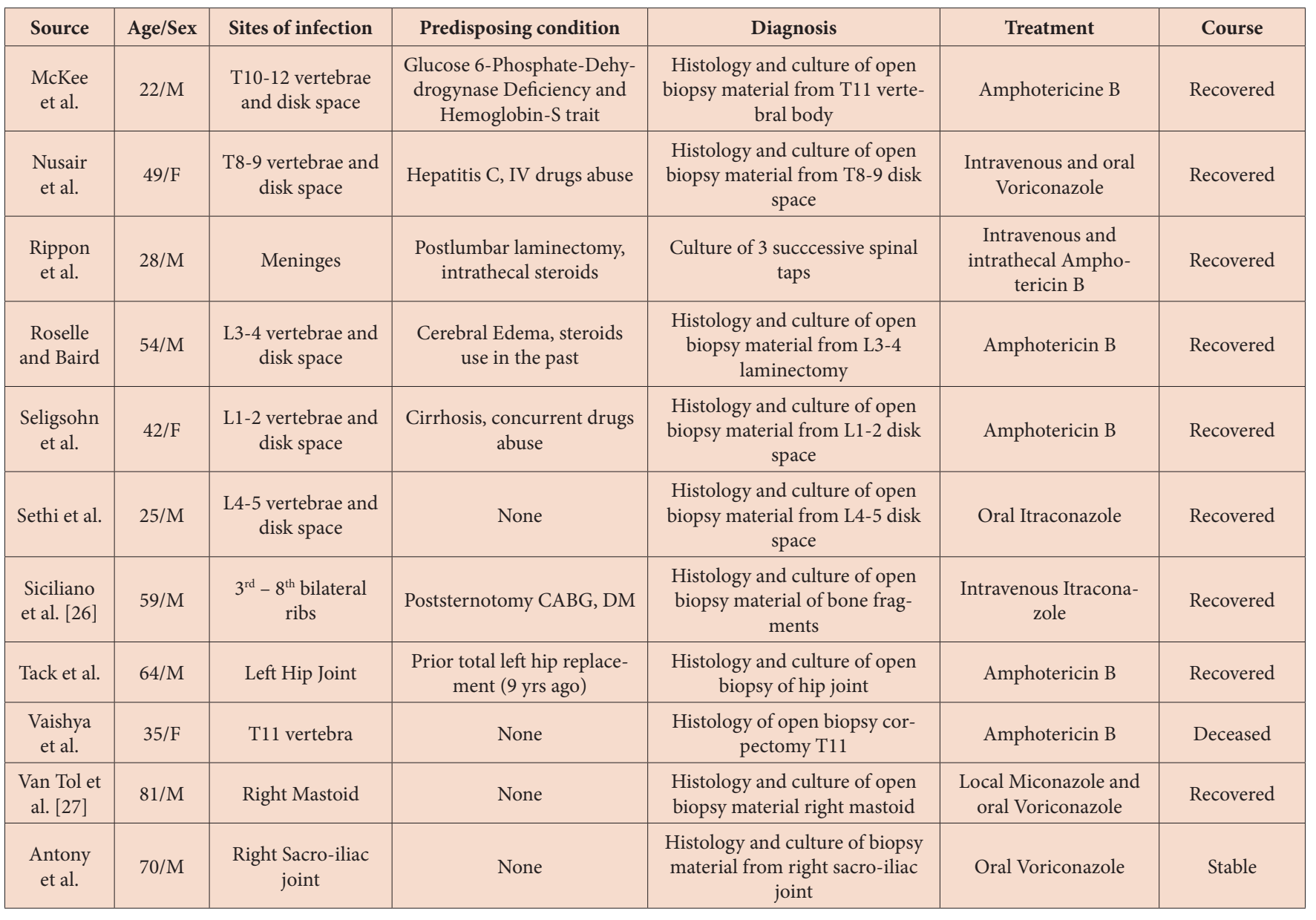




\section{References}

1. Gamaletsou MN, Rammaert B, Bueno MA, Moriyama B, Sipsas NV, et al. (2014) Aspergillus Osteomyelitis: Epidemiology, Clinical Manifestations, Management and Outcome. J Infect 68: 478-93.

2. Tack KJ, Rhame FS, Brown B, Thompson RC (1982) Aspergillus Osteomyelitis. Report of Four Cases and Review of Literature. Am J Med 73: 295-300.

3. Baez-Escudero JL, Greene JN, Sandin RL (2000) Case Report-Primary Sternal Aspergillus Osteomyelitis. Medscape Infectious Medicine 17.

4. Cimerman M, Gunde-Cimerman N, Zalar P, Perkovic T (1999) Femur Osteomyelitis due to a Mixed Fungal Infection in a Previously Healthy Man. J Clin Microbiol 37: 1532-5.

5. Grossman M (1975) Aspergillosis of Bone. British J Radiology 48: 57-9.

6. Roselle GA, Baird IM (1979) Aspergillus flavipes Group Osteomyelitis. Arch Intern Med 139: 590-2.

7. Walsh TJ, Anaissie EJ, Denning DW, Herbrecht R, Kontoyiannis DP, et al. (2008) Treatment of Aspergillosis: Clinical Practice Guidelines of the Infectious Diseases Society of America. Clin Infect Dis 46: 327-60.

8. Byrd BF, Weiner MH, McGee ZA (1982) Aspergillus Spinal Epidural Abscess. JAMA 248: 3138-9.

9. McKee DF, Barr WM, Bryan CS, Lunceford EM (1984) Primary Aspergillosis of The Spine Mimicking Pott's Paraplegia. J Bone Joint Surg Am 66: 1481-3.

10. Mohammadpour M, Mamishi S, Oaji M, Pourpak Z, Parvaneh N (2010) Successful Treatment of Fungal Osteomyelitis with Voriconazole in a Patient with Chronic Granulomatous Disease. Iran J Pedia 20: 487-90.

11. Raj KA, Srinivasamurthy BC, Sinduja MGI (2013) A Rare Case of Spontaneous Spondylodiscitis with Epidural Abscess in a 45-years-old Immunocompetent Female. J Craniovertebral Junction Spine 4: 82-4.

12. Sethi S, Siraj F, Chopra P (2012) Aspergillus Vertebral Osteomyelitis in Immunocompetent Patients. Ind J Orth 46: 246-50.

13. Nusair A, Smith P (2007) Aspergillus Vertebral Osteomyelitis in an Immunocompetent Host Treated with Voriconazole. Infectious Disease Clinical Practice 15: $122-4$.

14. Brown DL, Musher DM, Taffett GE (1987) Hematogenously Acquired Aspergillus Vertebral Osteomyelitis in seemingly Immunocompetent Drug Addicts. West J Med 147: 84-5.

15. Vaishya S, Sharma MS (2004) Spinal Aspergillus Vertebral Osteomyelitis with Extradural Abscess; Case Report and Review of Literature. Surg Neurol 61: 551-5. 16. D'sa SR, Singh S, Matthews P (2013) Case Report of Aspergillus Osteomyelitis of The Ribs in an Immunocompetent Patient. J Glob Infect Dis 5: 118-20.

17. Karthaus M (2011) Prophylaxis and Treatment of Invasive Aspergillosis with Voriconazole, Posaconazole and Caspofungin - Review of Literature. Eur J Med Res 16: 145-52.

18. Ingwer I, McLeish KR, Tight RR, White AC (1978) Aspergillus fumigatus Epidural Abscess in a Renal Transplant Recipient. JAMA Internal Medicine 138: 153-4.

19. McKee DH, Cooper PN, Denning DW (2000) Invasive Aspergillosis in a Patient with MELAS Syndrome. J Neuro Neurosurg Psychiatry 68: 765-7.

20. Seligsohn R, Rippon JW, Lerner SA (1977) Aspergillus terreus Osteomyelitis. Arch Internal Medicine 137: 918-20.

21. Asdamongkol N, Watcharananan SP, Chanplakorn P, Chongtrakool P, Suwatanapongched T, et al. (2011) Vertebral Osteomyelitis due to Aspergillus fumigatus. Case Report. Inter hospital Case Conference on Infectious Diseases Bangkok, Thailand.

22. Oh IS, Seo JY, Ha KY, Kim YC (2009) Treatment for Multiple Aspergillus Spondylitis including a Hip Joint. Asian Spine J 3: 106-12.

23. Asare KA, Jahng M, Pincus JL, Massie L, Lee SA (2013) Sternal Osteomyelitis caused by Aspergillus fumigatus following Cardiac Surgery: Case and Review. Medical Mycology Case Reports 2: 4-6.

24. Golmia R, Bello I, Marra A, Hamerschlak N, Osawa A, et al. (2011) Aspergillus fumigatus Joint Infection: a review. Semin Arthritis and Rheum 40: 580-4.

25. Allen D, Ng S, Beaton K, Taussig D (2002) Sternal osteomyelitis caused by Aspergillus fumigatus in a patient with previously treated Hodgkin's disease. J Clin Path 55: 616-8.

26. Siciliano RF, Waisberg DR, Samano MN, Leite PF, Junior PT, et al. (2012) Poststernotomy Aspergillosis: Successful Treatment with Voriconazole, Surgical Debridement and Vacuum-Assisted Closure Therapy. Clinics 67: 297-9.

27. Van Tol A, Van Rijswijk J (2009) Aspergillus Mastoiditis presenting with Unexplained Progressive Otalgia, in an Immunocompetent (older) Patient. Eur Arch Otorhinolaryngol 266: 1655-7.

28. Yun Yu OH, Wong Keet AW, Sheppard DC, Brewer T (2010) Articular Aspergillosis. Case Report and Review of the Literature. Inter J Infect Dis 14: e433-5.

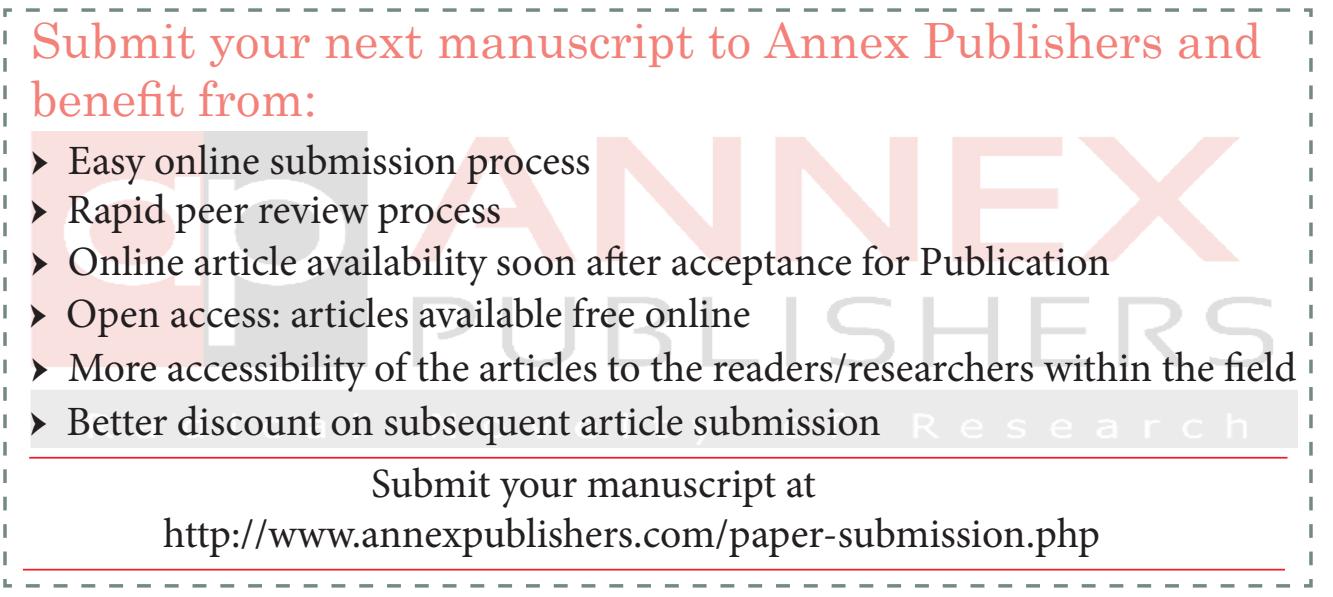

